\title{
FLORA DE GRÃO-MOGOL, MINAS GERAIS: EBENACEAE ${ }^{1}$
}

\author{
MATHEUS FORTES SANTOS* \& PAULO TAKEO SANO* \\ Departamento de Botânica, Instituto de Biociências, Universidade de São Paulo, \\ Caixa Postal 11461, 05422-970 - São Paulo, SP, Brasil \\ * Bolsistas do $\mathrm{CNPq}$
}

Candolle, A. De 1844. Ebenaceae. In A.L.P.P. De Candolle (ed.) Prodomus systematis naturalis regni vegetabilis. Fortin, Masson \& Sociorum. Paris, vol. 8, p. 209-243.

HIERN, W.P. 1873. A monograph of Ebenaceae. Trans. Cambridge Philos. Soc. 12(1): 27-300, pl. 1-11.

MrQuel, F.A.G. 1856. Ebenaceae. In C.F.P. Martius (ed.) Flora brasiliensis. Frid. Fleischer. Leipzig, vol. 7, p. 2-19, tab. $1-3$.

WALLNÖFER, B. 2001. The biology and systematics of Ebenaceae: a review. Ann. Naturhist. Mus. Wien 103(B): 485-512.

\section{Diospyros. L.}

Árvores, arbustos ou subarbustos dióicos, raramente monóicos ou poligâmicos. Folhas perenes, raramente decíduas, filotaxia alterna (oposta ou suboposta), margem inteira. Inflorescência axilar, cimosa ou fasciculada, ou flores solitárias, principalmente as pistiladas. Flores geralmente dimórficas, as estaminadas freqüentemente menores que as pistiladas; cálice acrescente no fruto, 3-8-lobado, raramente íntegro ou polissépalo; corola 3-8-lobada; disco nectarífero desenvolvido ou não, muitas vezes fimbriado. Flores estaminadas com 2 a ca. 100 estames, anteras rimosas; estaminódios presentes ou ausentes, geralmente conspícuos; pistilódio de conspícuo a ausente. Flores pistiladas com ovário globoso, ovóide ou cônico, glabro ou piloso, 2-8-carpelar, em poucas espécies unilocular, ou na maioria das espécies bilocular por intrusão placentária, carpelos 2-ovulados; ramos do estilete 2-8. Fruto baga; sementes 1-16, geralmente comprimidas, algumas vezes cilindricas ou levemente irregulares.

1. Lâmina foliar estreitamente elíptica a lanceolada, face adaxial pilosa apenas na nervura central,

face abaxial densamente serícea; pecíolo 1-4 mm compr. Estames mais de 20 por flor D. sericea

1'. Lâmina foliar ovada a obovada ou largamente elíptica, face adaxial pubérula a glabra, face abaxial

pilosa, não-serícea; pecíolo 5-12 mm compr. Estames cerca de 15, não chegando a 20 por flor.

2. Lâmina foliar ovada a obovada (largamente elíptica), ambas as faces com pilosidade ferrugínea quando jovens, quando maduras face abaxial híspida a pubérula; pecíolo 5-7 mm compr. Corola membranácea, pilosa externa e longitudinalmente apenas na parte central de cada lobo. Estames de comprimento subigual entre si D. hispida

2'. Lâmina foliar elíptica a subovada, ambas as faces com pilosidade marrom-avermelhada quando jovens, quando maduras face abaxial esparsamente pilosa; pecíolo 10-12 $\mathrm{mm}$ compr. Corola carnosa, externamente glabra ou com indumento esparso. 3 estames bem menores que os demais D. keturn

\subsection{Diospyros hispida A.DC. in A.DC., Prodr. 8: 236. 1844.}

Arvoretas 0,7-4,0 $\mathrm{m}$ alt., dióicas, ramos cilíndricos, pubérulos quando jovens, ramos maduros em geral glabros. Folhas alternas; pecíolo 5-7 mm compr.; lâmina ovada a obovada (largamente elíptica), 3,5-21,6 cm compr., 1,9-7,7 cm larg., ambas as faces com pilosidade ferrugínea quando jovens, quando maduras face adaxial pubérula, brilhante, face abaxial híspida a pubérula, ferrugínea, ápice agudo ou arredondado, base arredonda-

1 Trabalho realizado conforme o planejamento apresentado por Pirani el al. (2003). Bol. Bot. Univ. São Paulo 21(1): 1-24. 
da ou atenuada. Flores solitárias, axilares, esverdeadas, 4-meras; cálice piloso em ambas as faces; corola membranácea, externa e longitudinalmente pilosa apenas na parte central de cada lobo, internamente glabra. Flores estaminadas: ca. 12 estames, epipétalos, geminados, heterodínamos, filete piloso, conectivo piloso na base, rostrado; pistilódio piloso. Flores pistiladas: ovário piloso; ramos do estilete fendidos irregularmente até a base. Baga globosa; semente comprimida. (Fig. 1. A-B)

Cordeiro et al. CFCR 11569 (SPF); Pirani et al. CFCR 13189 (SPF, W).

Material adicional: São Paulo. Kuhlmann 3698 (SP); Sakane 599 (SP).

Esta espécie ocorre no Brasil Central e nordeste brasileiro, desde o Ceará, Piauí e Maranhão até o Mato Grosso do Sul e Paraná. Trata-se de planta seletiva xeromórfica, que ocorre exclusivamente em cerrados e campos cerrados. Floresce de agosto a novembro. Os frutos amadurecem em dezembro-março.

1.2. Diospyros ketun B. Walln., Ann. Naturhist. Mus. Wien $101(B): 573.1999$.

Árvores 7,0 $\mathrm{m}$ alt., dióicas; ramos cilíndricos, indumento marrom-avermelhado quando jovens, ramos maduros em geral glabros. Folhas alternas; pecíolo 10$12 \mathrm{~mm}$ compr.; lâminas elípticas a subovais, (4)10-19 cm compr., (2,5) 4,5-8,7 cm larg., ambas as faces com pilosidade marrom-avermelhada quando jovens, quando maduras face adaxial levemente lustrosa e glabra, face abaxial esparsamente pilosa, ápice agudo, base atenuada. Inflorescência axilar, 1-2 flora. Flores estaminadas 4-meras; cálice persistente, espessado na base, piloso na parte interna e basal, lobos agudos; corola verde no botão floral, carnosa, externamente glabra ou com indumento esparso e alvo, internamente glabra; estames 15 , inseridos próximo à base da corola, às vezes geminados, 3 bem menores que os demais. Baga globosa, solitária, glabra quando madura. (Fig. 1. C)
Kameyama et al. CFCR 8880 (holótipo, W; isótipo, SPF); Pirani et al. CFCR 8486 (parátipo, BHCB, SPF).

Esta espécie ocorre em Grão-Mogol e Nova Lima, Minas Gerais. Habita matas ciliares. Foi colhida com flor em Grão-Mogol em setembro. Ainda não há descrição da flor pistilada pois trata-se de uma espécie recentemente descrita, da qual foram coletados apenas indivíduos estaminados ou frutíferos.

\subsection{Diospyros sericea A.DC. in A.DC., Prodr. 8: 236. 1844.}

Árvores 1,5-7,0 m alt., dióicas; ramos cilíndricos, indumento seríceo quando jovens, ramos maduros em geral glabros. Folhas alternas, dísticas; pecíolo $1-4 \mathrm{~mm}$ compr.; lâmina estreitamente elíptica a lanceolada, 1,97,9 cm compr., 0,8-2,0 cm larg., face adaxial verde-escura, brilhante, pilosa apenas na nervura central, face abaxial verde-clara, opaca, densamente serícea, ápice agudo, base obtusa. Inflorescência cimosa. Flores axilares, 4-6meras; cálice piloso; corola creme, membranácea, serícea apenas na face externa. Flores estaminadas 1-3; estames mais de 20, creme, epipétalos, heterodínamos, conectivo rostrado, pistilódio seríceo. Flores pistiladas solitárias; ovário amarelo-ouro, seríceo, lóculos uniovulados; ramos do estilete concrescidos quase até o ápice, fendidos irregularmente, pilosos; estigmas creme; estaminódios presentes, adnatos à corola. Baga globosa; semente comprimida. (Fig. 1. D-G)

Hatschbach 41252 (MBM, SPF); Pirani et al. CFCR 868 (SPF, W), CFCR 11341 (SP, SPF, W); Sano et al. CFCR 12537 (F, G, HUEFS, K, MBM, RB, SPF, UB, W); Silva et al. CFCR 13487 (NY, SPF, W); Zappi et al. CFCR 12023 (SPF, W).

Esta espécie distribui-se pelos cerrados e matas ciliares desde o Piauí até Goiás, passando pela Bahia e Minas Gerais. Floresce de abril a dezembro. 


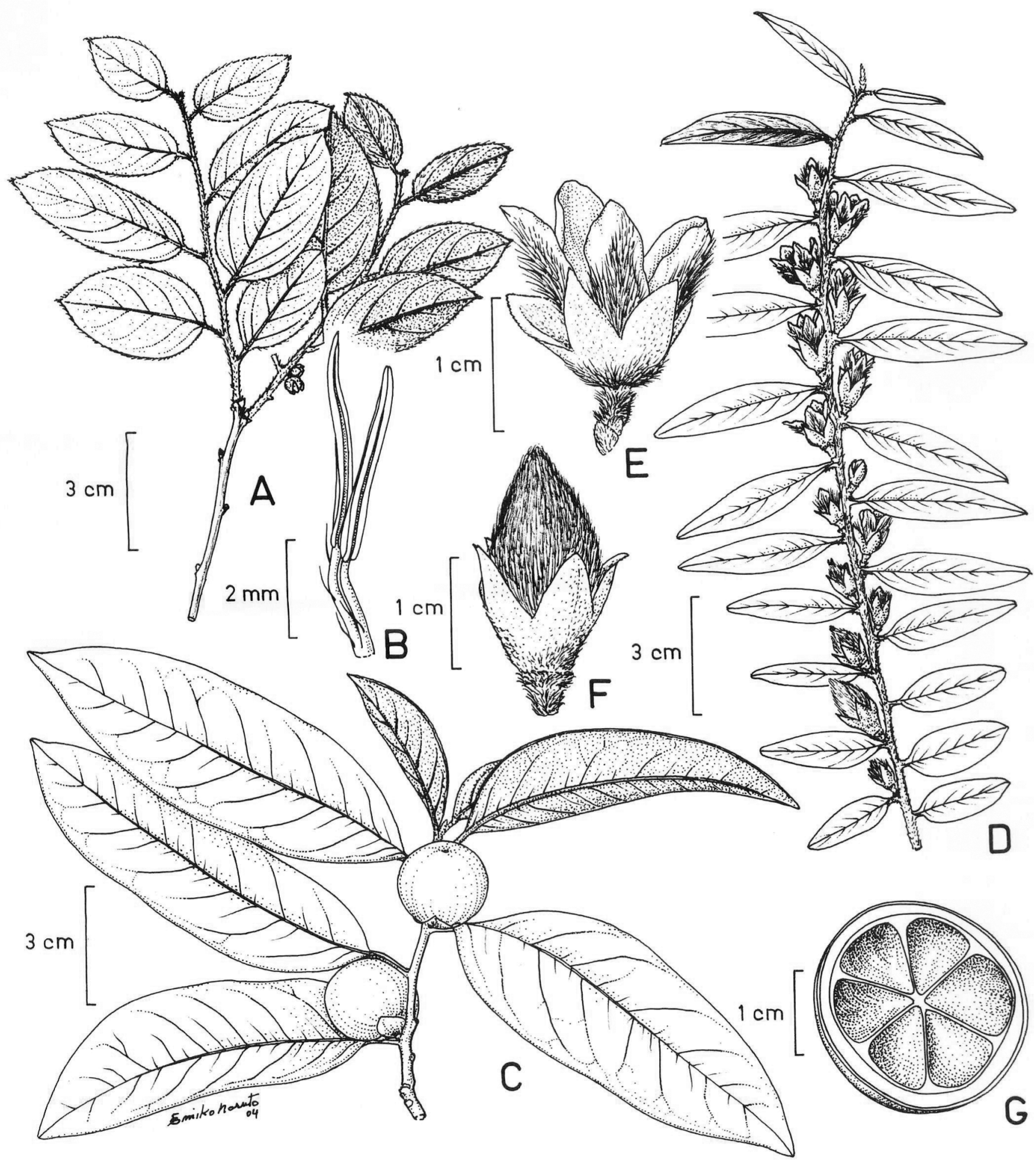

Fig. 1. EBENACEAE. A-B. Diospyros hispida. A. Aspecto geral do ramo com flores; B. Estames geminados em vista lateral. C. D. ketun. Aspecto geral do ramo com frutos. D-G. D. sericea. D. Aspecto geral do ramo com flores e frutos imaturos; E. Flor em vista lateral; F. Fruto em vista lateral; G. Fruto em corte transversal mediano. (A-B. Comleiro el al. CFCR 11569), C. Kameyama et al. CFCR 8880; D-G, Sano et al. CFCR 12537). 